
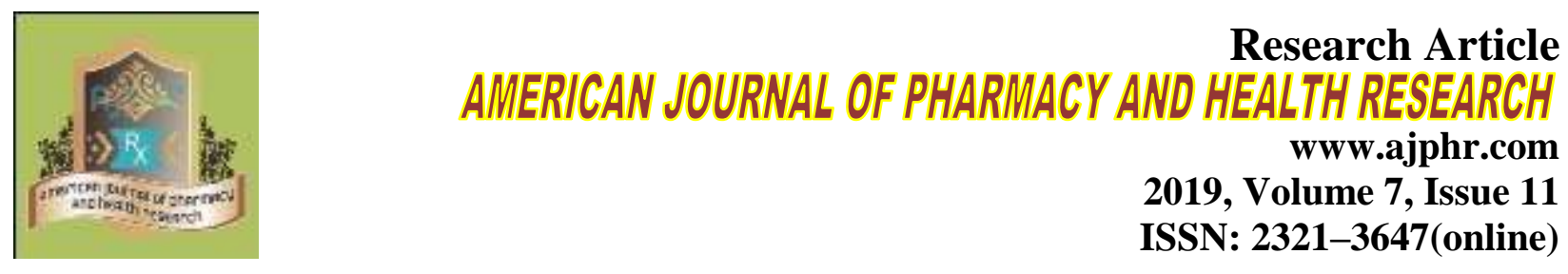

\title{
Biosynthesis of Copper Nanoparticles Using Aqueous Ficus Racemosa Extract- Characterization and Study of Antimicrobial Effects
}

\author{
Gaurav Mishra' ${ }^{1}$, Vivek Yadav ${ }^{1}$, Dr Alka Saxena ${ }^{2 *}$ \\ 1.G.C.R.G. Memorial Trust's Group of Institutions, Faculty of Engineering, Lucknow \\ 2.R\&D Department, Acube Life Sciences, Lucknow, Uttar Pradesh, India.
}

\begin{abstract}
Development of green nanotechnology is generating interest of researchers toward ecofriendly biosynthesis of nanoparticles. In this study, biosynthesis of stable copper nanoparticles were done using Ficus Racemosa leaf extract. First we prepared leaf extract of Ficus Racemosa sanctum in deionised water. This extract added to $0.02 \mathrm{M}$ of copper sulfate solution and we observed the change in color of the solution from colorless to colored solution, this indicates that there is a formation of $\mathrm{Cu}$ nanoparticles. These biosynthesized $\mathrm{Cu}$ nanoparticles were characterized with the help of UV - Visible Spectroscopy. It was observed that the Ficus Racemosa leaf extract can reduce copper ions into copper nanoparticles within 8 to $10 \mathrm{~min}$ of reaction time. Thus, this method can be used for rapid and ecofriendly biosynthesis of stable copper nanoparticles. Further, microscopic examination and antimicrobial activity of synthesized nanoparticles was done against several bacteria and fungi.
\end{abstract}

Keywords: Nano-biotechnology, Spectrophotometer, Nanoparticles, Physico-chemical properties, UV -Visible Spectroscopy, antimicrobial activity 


\section{INTRODUCTION}

Nanoparticles represent a particle with a nanometer size of $1-100 \mathrm{~nm}$. The nanoscale material has new, unique, and superior physical and chemical properties compared to its bulk structure, due to an increase in the ratio of the surface area per volume of the material/particle [1].

A number of Indian traditional systems of medicines occur in India, of which prominent is Ayurveda. It's in existence for around 3000 years. Ayurvedic preparations have been successfully used for the treatment of various ailments from treating snake bites, to wound healing, with skin ointments protecting from infections, controlling anxiety, increasing memory and sharpening the overall beauty of a person.

The genus Ficus is an important group of trees which has various chemical constituents of promisive medicinal value. It is a sacred tree of Hindus and Buddhists. Four species of this genus constitute the group "Nalpamaram", namely; F. racemosa, F. microcarpa, F. benghalensis and F. religiosa (Athi, Ithi, Peral and Arayal respectively).

Ficus racemosa is also known as F. Glomerata. Ficus racemosa has various synonyms like Udumbara (Udumbara is considered sacred to God Dattaguru), yajnanga, yajniya, yajnayoga, yajnyasara, gular, Cluster Fig tree, Country fig tree etc. It has been used in ritual sacrifice. It is one of the ksirivriksa - latex oozes out when the leaves are cut or plucked. It is one of the plants from a group, called pancavalkala, meaning the thick bark skins of five herbs, viz. udumbara, vata, asvattha, parisa and plaksa. The decoction of pancavalkala is used internally or for giving enema in bleeding per rectum and vagina (Raja Nighantu). Maharishi Charka has categorized udumbara as mutrasangrahaniya - anti-diuretic herb. Susruta has described the properties of the plant, like astringent, promotes callus healing in fractures (bhagnasandhaniya), alleviates Rakta pitta, burning sensation and obesity, and useful in vaginal disorder. Different parts of Ficus Racemosa are traditionally used as fodder, edible and ceremonial [2]. All parts of this plant (leaves, fruits, bark, latex, and sap of the root) are medicinally important in the traditional system of medicine in India. The astringent nature of the bark has been employed as a mouth wash in spongy gum and also internally in dysentery, menorrhagia and haemoptysis [3]. The bark is antiseptic, antipyretic and vermicidal, and the decotion of bark is used in the treatment of various skin diseases, ulcers and diabetes. It is also used as a poultice in inflammatory swellings/boils and regarded to be effective in the treatment of piles, dysentry, asthma, gonorrhea, gleet, menorrhagia, leucorrhea, hemoptysis and urinary diseases [4]. 

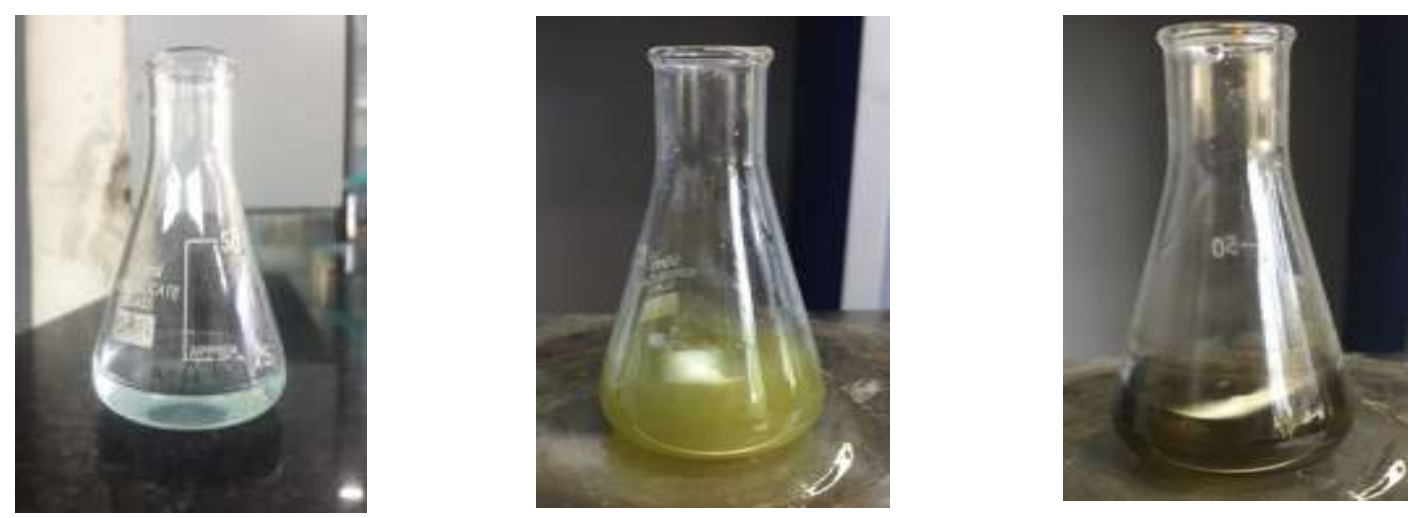

Figure 1: Synthesis of Copper Nanoparticles

\section{TAXONOMY}

\begin{tabular}{|l|l|}
\hline Kingdom & Plantae \\
\hline Division & Magnoliophyta \\
\hline Class & Magnolipsida \\
\hline Order & Urticales \\
\hline Family & Moraceae \\
\hline Genus & Ficus \\
\hline Species & racemosa \\
\hline
\end{tabular}

Various part of ficus racemosa linn are use in the treatment of various disease [5].

Roots: Roots are used in diabetes and pectoral complaints. Roots are also applied in mumps and other inflammatory glandular enlargements, also in hydrophobia

Bark : Bark is useful in diabetes, urological disorder and leprosy. It is highly effective in threatened abortion. The bark exhibited hypoglycemic effect in normal and alloxan-induced hyperglycemic animals and b- sitosterol-D-glucoside was identified as the active principle. The bark exhibited hypoglycemic effect in normal and alloxan-induced hyperglycemic animals and b- sitosterol-D-glucoside was identified as the active principle.

Leaves: The leaves are good for washing the wounds and ulcer. They are also useful in diarrhea and dysentery.

Fruit: The fruit are useful in the treatment of leucorrhoea and blood disorder. They are also useful in miscarriage, menorrhagia, cancer and visceral obstructions.

\section{Need For Green Synthesis}

Green synthesis of nanoparticles is a bottom up approach where the reaction occurring is reduction/oxidation. Nanoparticles can be prepared by different methods. Chemical approaches 
are the most popular methods for the production of nanoparticles. However, some chemical methods cannot avoid the use of toxic chemicals in the synthesis protocol. The chemically synthesized nanoparticles carry some reactive functional groups, which can be toxic to biological system. Hence, the development of clean, biocompatible, non-toxic and eco-friendly methods for the synthesis of nanoparticles deserves merit. The green synthesis of metallic nanoparticles (NPs) has attracted tremendous attention in recent years because these protocols are low cost and more environmentally friendly than standard methods of synthesis [6].

\section{MATERIALS AND METHOD}

All the chemical reagents used in this experiment were of analytical grade purchased from Himedia. The Ficus racemosa leaves were collected from in and around Lucknow, Uttar Pradesh . Thoroughly washed leaves $(5 \mathrm{~g})$ were cut and boiled with $20 \mathrm{ml}$ of de-ionized water for $15 \mathrm{~min}$ in heating mental at temperature $80^{\circ} \mathrm{C}$. The resulting product was filtered and stored in refrigerator for further experiments.

\section{Preparation of Plant Leaf Extract}

The freshly chopped Ficus racemosa leaves were weighed $5 \mathrm{~g}$ and mixed in $20 \mathrm{ml}$ of distilled water and boiled for $15 \mathrm{~min}$ at $80^{\circ} \mathrm{C}$. The extract was allowed to cool at room temperature and filtered by Whatmann Nolfilter Paper. The filtrate was stored in a beaker tightly seal packed with aluminium foil and paraffin and kept at room temperature for further use. $20 \mathrm{ml}$ of extract was placed in a clean and dry beaker and heated to dryness over water bath [7].

\section{Phytochemical Tests [8]}

Alkaloid Test: Wagner's reagent was prepared by adding $2 \mathrm{~g}$ of iodine and $6 \mathrm{~g}$ of KI in $1000 \mathrm{ml}$ of water and then $1 \mathrm{ml}$ of plant extract was added to $1 \mathrm{ml}$ of above reagent. A reddish brown precipitate indicates the presence of alkaloids in the plant extract.

Saponin Test: $1 \mathrm{ml}$ of plant extract was added to 5 to $10 \mathrm{ml}$ of distilled water. The test tube was shaken well to note a stable froth. The froth formation indicates the presence of saponin in the plant extract.

Tannin Test: $5 \%$ ferric chloride solution was prepared. $2 \mathrm{ml}$ of $5 \%$ ferric chloride solution was added to $1 \mathrm{ml}$ of plant extract. The color change which gives blue, black or dark green color indicates the presence of tannin in the plant extract.

Flavonoid Test: $1 \% \mathrm{NaOH}$ was prepared by dissolving $10 \mathrm{~g}$ of sodium hydroxide in $1 \mathrm{~L}$ of distilled water. $2 \mathrm{ml}$ of $1 \% \mathrm{NaOH}$ was added to $1 \mathrm{ml}$ of plant extract. The yellow coloration indicates the presence of flavonoid in the plant extract. 
Starch Test: 2 drops of iodine solution was added to $2 \mathrm{ml}$ of plant extract. The blue-black colour observed indicates the presence of starch in the plant extract.

Carbohydrate Test: Fehling A was prepared by adding $7 \mathrm{~g}$ of copper sulphate in $100 \mathrm{ml}$ distilled water with 2 drops of sulphuric acid to the reagent. Fehling B was prepared by adding 35g of potassium sodium tartarate and $12 \mathrm{~g}$ of sodium hydroxide in $100 \mathrm{ml}$ of distilled water. $0.5 \mathrm{ml}$ of Fehling A and Fehling B was added to the $0.5 \mathrm{ml}$ of plant extract. The mixtures were then boiled and the formation of brick red precipitate of cuprous oxide indicates the presence of carbohydrate in the plant extract.

Protein Test: $0.5 \%$ of copper sulphate and $0.5 \%$ of $10 \% \mathrm{NaOH}$ was added to $1 \mathrm{ml}$ plant extract. The purple coloration indicates the presence of protein in the plant extract.

Fat Test: $1 \mathrm{ml}$ of distilled water and few drops of ethanol were added to $1 \mathrm{ml}$ of plant extract. The white colour precipitate indicates the presence of fat in the plant extract.

\section{Preparation of 0.02M Solution of Copper Sulphate}

The solution used in synthesizing copper nanoparticles was analytical grade copper sulphate. A $0.02 \mathrm{M}$ stock solution of $\mathrm{CuSO}_{4} .5 \mathrm{H}_{2} \mathrm{O}$ in chloride free distilled water was prepared. $0.031 \mathrm{~g}$ of Copper Sulphate was transferred in a $50-\mathrm{ml}$ beaker and $20 \mathrm{ml}$ de-ionized water was added dropwise while swirling to dissolve the salt. The beaker containing solution was tightly covered with aluminium foil and paraffin and kept away from light for further use[9].

\section{Synthesis of Copper Nanoparticles:}

$0.02 \mathrm{M}$ copper sulphate was prepared in $5 \mathrm{ml}$ distilled water for each synthesis and blue solution was seen. Glycerine $(500 \mu l)$ was added to aqueous solution containing copper sulphate with vigorous stirring. $10 \mathrm{ml}$ plant extract was added to copper sulphate solution with glycerine. Sodium hydroxide $(500 \mu \mathrm{l})$ was added dropwise under rapid stirring. Colour changes from light to dark green. Reduction started and greenish brown colour formation confirms formation of copper nanoparticles.

\section{Purification of Nanoparticles}

The reaction mixture was centrifuged at the speed of $5000 \mathrm{rpm}$ and the supernatants were taken out by aspiration. This clear light green liquid was analysed by a UV-Visible spectrophotometer. The content/residue was washed in double distilled water thrice, centrifugation was repeated at $5000 \mathrm{rpm}$ for 30 minute and powder was collected and dried in hot air oven at $110^{\circ} \mathrm{C}$ for 3 hours. These oven-dried particles were used for further analysis for determining size, shape and chemical composition.

\section{Characterization of Nanoparticles:}


UV - Visible spectrophotometer: The peak of the nanoparticles should be in the range of 400-600 $\mathrm{nm}$. Best nanoparticles are synthesized at $420 \mathrm{~nm}$ having sharp peak .Microscopic examination of nanoparticles: was done by mounting the nanoparticles with water and safranin and visualizing under the light microscope[10].

\section{Antimicrobial Activity}

\section{Test organism for antibacterial activity}

Gram positive (+) bacteria and gram negative (-) bacteria, and fungus were used for determining antimicrobial activity. The bacterial pathogens were collected from the Department of Biotechnology, MNNIT. The bacteria used are as follows

\section{List of microbes:}

\begin{tabular}{lll}
\hline S No. & Name of the Microbes & Bacterial type \\
\hline 1 & E. Coli & Gram negative \\
2 & S.aureus & Gram positive \\
3 & B.subtilis & Gram positive \\
4 & A.niger & - \\
5 & F.Oxysporum & - \\
\hline
\end{tabular}

The bacterial and fungus strains were grown and maintained on nutrient agar and potato dextrose agar slant at $37^{\circ} \mathrm{C}$, followed by incubation for 5 days. The culture was stored at $4{ }^{\circ} \mathrm{C}$ for further use. The organisms were sub cultured once in every 15 days [11].

\section{Media preparation}

In this study, Nutrient Agar and Potato Dextrose Agar medium was used which supports growth of a wide range of bacteria including Bacillus subtilis and Escherichia coli. For preparing nutrient agar and Potato Dextrose Agar medium both the powders were accurately weighed and were dissolved in distilled water. The medium was kept in cotton- plugged glass container, sterilized in an autoclave at $121^{\circ} \mathrm{C}$ for 15 mins. It was distributed inside a laminar hood on petri dishes hot $45^{\circ} \mathrm{C}$ and allowed to solidify.

\section{Method for Testing Antimicrobial Activity of Synthesized Copper Nanoparticles}

Antimicrobial activity of biological synthesized Copper nanoparticles was carried out by Agar well diffusion method against Gram negative and Gram positive bacteria and fungus. The pure culture of organism was sub cultured in nutrient broth and potato dextrose broth. The nutrient agar plates were prepared by $25 \mathrm{ml}$ (for one plate) of molten media into sterile petri-plates. For bacterial anf fungal growth, a culture was prepared by spreading the $30 \mu \mathrm{L}$ fresh culture with each test organism on nutrient agar plates with the help of a sterile glass rod spreader. Plates 
were left standing for 10 minutes to let the culture get absorbed. Then $6 \mathrm{~mm}$ (size) wells (4 well)were punched at four corners of each Petri dish at $1.5 \mathrm{~cm}$ away from the wall into nutrient agar plates for testing antimicrobial activity. Using the micro-pipette $50 \mu 1,75 \mu 1$ and $100 \mu 1$ of sample of nanoparticle suspension was poured into each well on the plates. Then antibioticCiprofloxacin was used as positive control against bacteria and antifungal drug fluconazole was used as positive control against different fungus. Using the micropipette, $10 \mu 1$ of positive control solution was poured into one of the well. After adding the samples in the wells, the dishes were keptin a refrigerator for an hour for absorption of the samples into the surrounding medium from the well. The plates were transferred into an incubator set at $37^{\circ} \mathrm{C}$ to allow bacterial growth on the medium. After $24 \mathrm{hrs}$ the plates were taken out of the incubator and observed for zone of inhibition around the wells. The zone of inhibition was measured in millimetres [12].

\section{RESULTS AND DISCUSSION:}

\section{Biosynthesis of copper nanoparticles from ficus plant extracts.}

In this study, copper nanoparticles were synthesized using ficus leaf extract under static condition. It is well known that copper nanoparticles exhibit dark green colour in aqueous solution due to excitation of surface plasmon vibrations in copper nanoparticles. As the extract was mixed in the aqueous solution of the copper ion complex, it started to change the colour from colourless to greenish brown due to reduction of copper ion which indicated formation of copper nanoparticles (Fig. 1).

\section{Phytochemical analysis of ficus leaf extracts}

The phytochemical characteristics of the medicinal plants investigated that are summarized in Table 1.

Table 1: Qualitative analysis of phytochemicals in the extract of ficus racemosa

\begin{tabular}{llll}
\hline Phytochemicals & Test & Observation & $\begin{array}{l}\text { Inference } \\
\text { Presence (+), } \\
\text { Absence(-) }\end{array}$ \\
\hline Alkaloid & & & + \\
Tannin and Phenolic compound & Lead acetate test & Green colour & + \\
Terpenoid and Phytosterol & Salkowaski test & Reddish-brown colour & + \\
Saponin & Foam test & Presence of emulsion & - \\
Flavonoid & Ferric chloride test & White precipitate & - \\
Glycoside & - & Brown ring & - \\
Carbohydrates & Fehling's test & - & + \\
Test for starch & Iodine test & - & - \\
Test for proteins & Biuret's test & - & - \\
Fixed oil and fatty acid & Spot test & Presence of spot & + \\
\hline
\end{tabular}


The results revealed that the medicinally active constituents such as phenol, alkaloids, Terpenoids, carbohydrates and fats were present in ficus leaf extract. While saponin, flavonoid, glycoside,starch and proteins were absent in ficus leaf extract.

\section{UV-Vis spectra analysis}

The UV-Vis spectroscopy recorded from the nanoparticle solution showed the characteristic surface plasmon resonance (SPR) spectra with absorbance at $250-700 \mathrm{~nm}$ and peak maximum at $280 \mathrm{~nm}$ which is attributed to the formation of $\mathrm{Cu}$ nanoparticles. The formation of the copper nanoparticle was considered successful by initial change in colour. (Fig. 3).

Microscopic examination of nanoparticles: was done by mounting the nanoparticles with water and safranin and visualizing under the light microscope which showed the pink colour structure of cells. (Fig. 2).

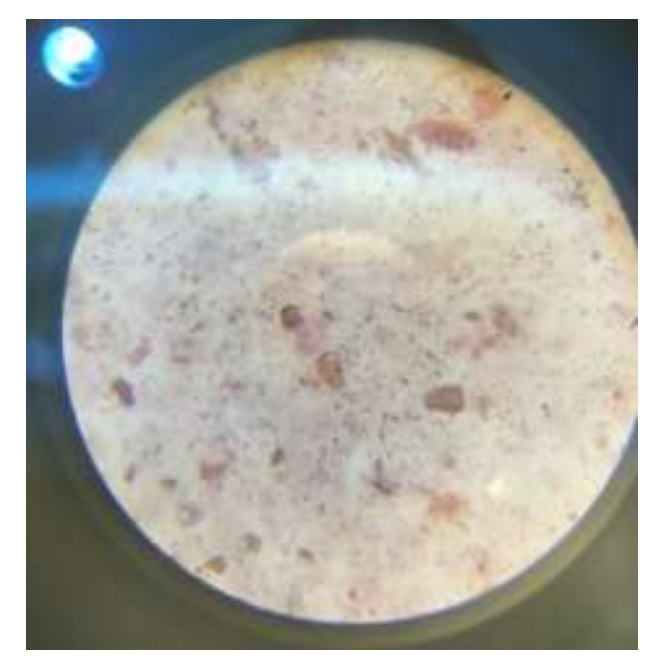

Figure 2: Microscopic examination of nanoparticles of Ficus racemosa 


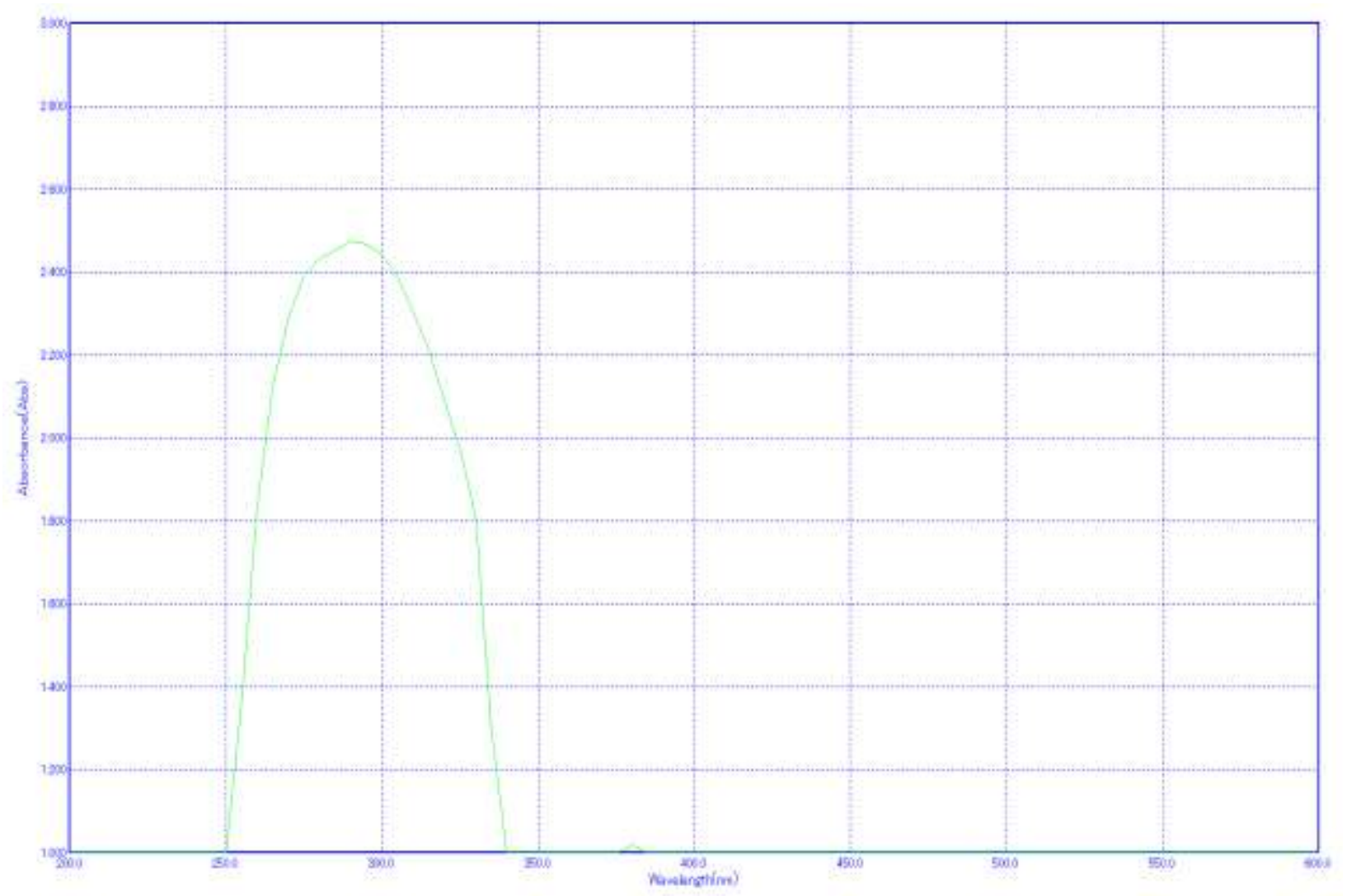

Figure 3: UV-Visible spectroscopy result for Ficus racemosa

\section{Antibacterial activity:}

The antimicrobial activity of Ficus racemosa stabilized copper nanoparticles against three pathogenic bacteria Bacillus subtilis, Escherichia coli and S.aureus and two fungus A.niger and F.Oxysporum were evaluated and was compared to a commercial antibiotic Ciprofloxacin and antifungal drug fluconazole. The distinct Zone of Inhibition was observed around the well where in the suspension of CuNPs was applied. (Table 1).

The size of inhibition zone differed according to the type of microbes and the size and concentrations of copper nanoparticles. The zone of inhibition was observed to be more in gram positive bacteria when compared to gram negative bacteria. This is mainly due to the differences in pathogen's membrane structures. The anti-bacterial activity of copper nanoparticles showed more inhibition than that of plant extracts (control). For copper nanoparticles, zone of inhibition was found to be $10 \mathrm{~mm}, 10 \mathrm{~mm}$ and $9 \mathrm{~mm}$ against Escherichia coli, Bacillus subtilis and Staphylococcus aureus respectively. The highest zone of inhibition has reported by the synthesized copper nanoparticles against Escherichia coli and Bacillus subtilis with $100 \mu 1$ concentration of CuNPs . (figure 4). 


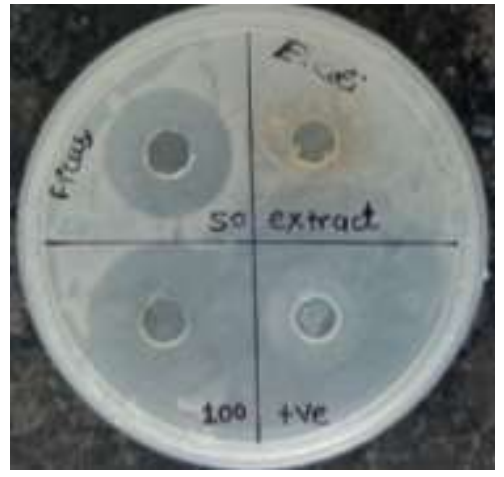

E. Coli

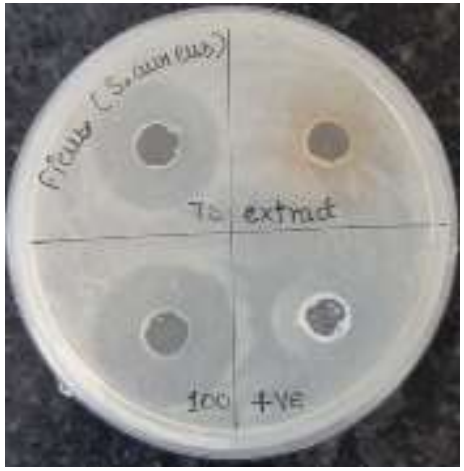

S.aureus

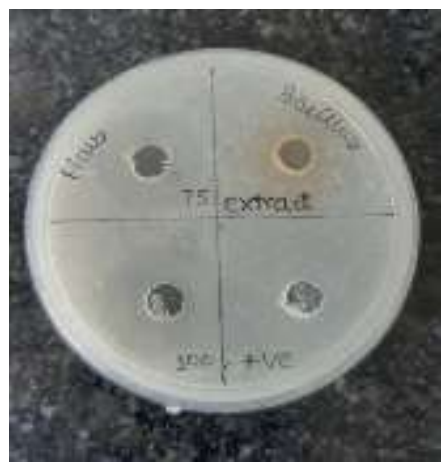

B.subtillus

Figure 4: Antibacterial activity of CuNPs from ficus leaf extract

\section{Anti-fungal Activity of ficus leaf}

The results of anti-fungal activity were show in Table 2 .

Table 2: Antimicrobial activity of CuNPs from ficus leaf extract

\begin{tabular}{llllll}
\hline Concentration $(\boldsymbol{\mu l})$ & \multicolumn{6}{l}{ Diameter of zone of inhibition(mm) bacteria } \\
& E. coli & B.subtilis & S.aureus & A.niger & F.Oxysporum \\
\hline 50 or 75 & 8 & 8 & 7 & 12 & 3 \\
100 & 10 & 10 & 9 & 13 & 6 \\
Extract & 7 & 7 & 5 & 7 & 0 \\
\hline Positive & 16 & 20 & 10 & 10 & 7 \\
\hline
\end{tabular}

Zone of inhibition was observed with the ficus leaf extract, flucanazole as a control and copper nanoparticles against fungal strain (Fusarium species and Aspergillus species). The anti-fungal activity of copper nanoparticles showed more activity than that of plant extracts. For copper nanoparticles from ficus leaf extract the zone of inhibition was found to be $13 \mathrm{~mm}$ for Aspergillus species and $6 \mathrm{~mm}$ for F.oxysporum species. The highest zone of inhibition has reported by the synthesized copper nanoparticles against Aspergillus species. On the other hand, plant extract did not exhibit sufficient antifungal activity. (figure 5). 


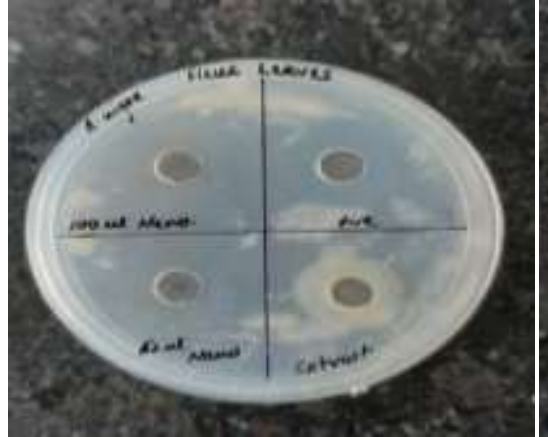

A.niger

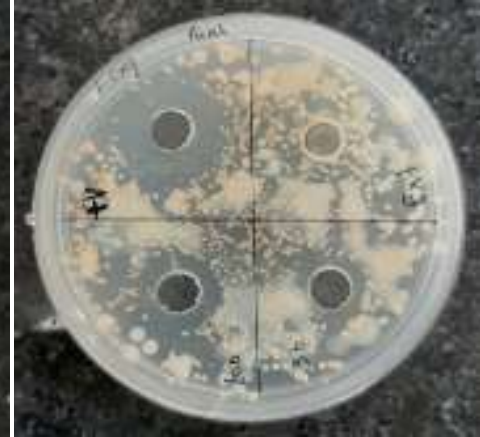

F.oxysporum

Figure 5: Antifungal activity of CuNPs from ficus leaf extract

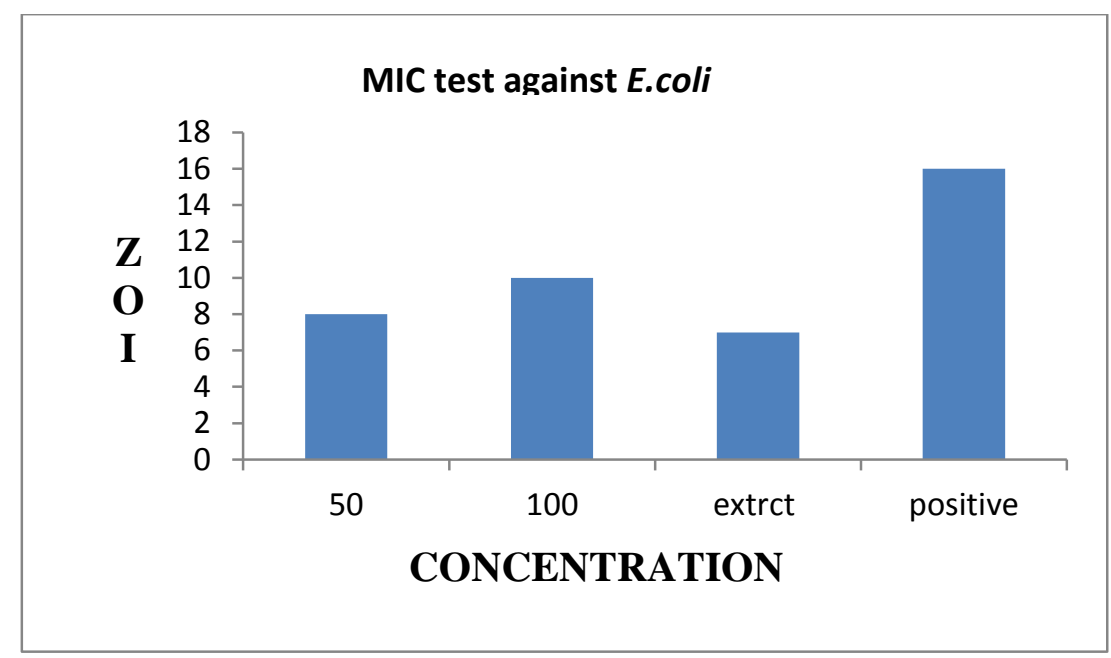

Graph 1: MIC against E. Coli

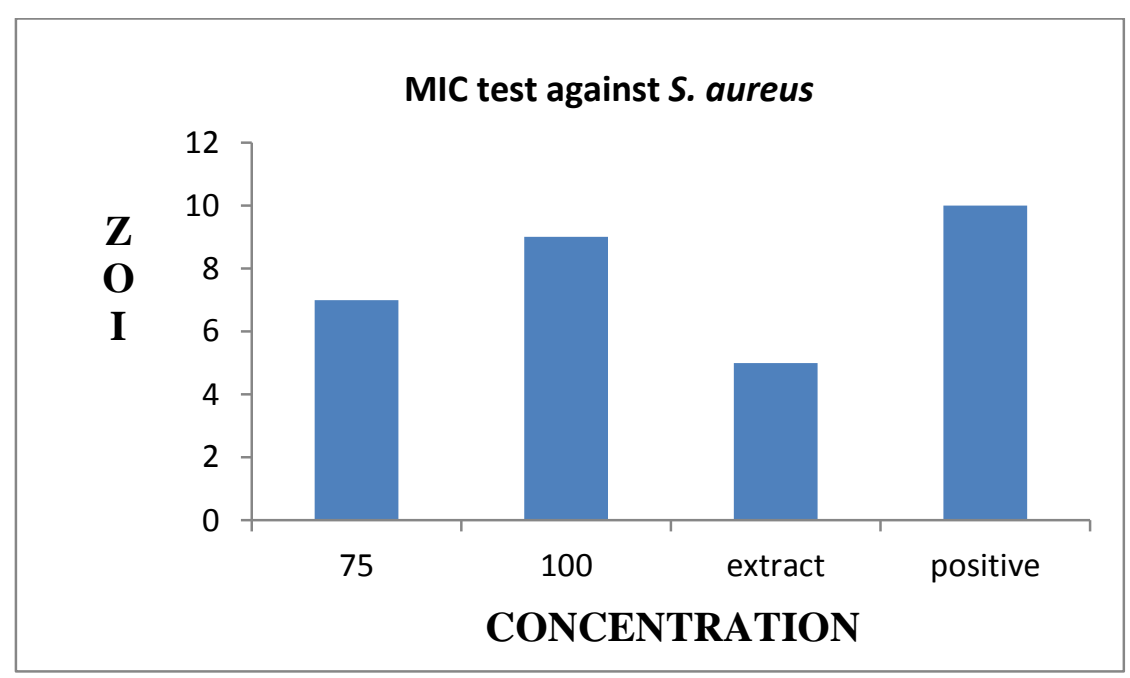

Graph 2: MIC against E. Coli 


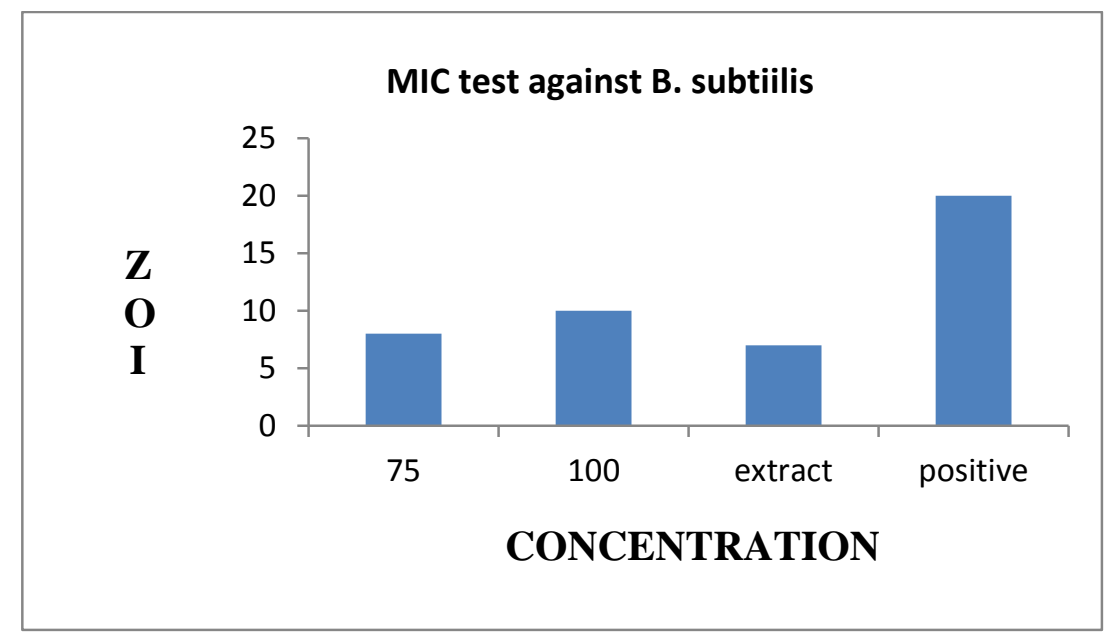

Graph 3: MIC Test against B.subtilis

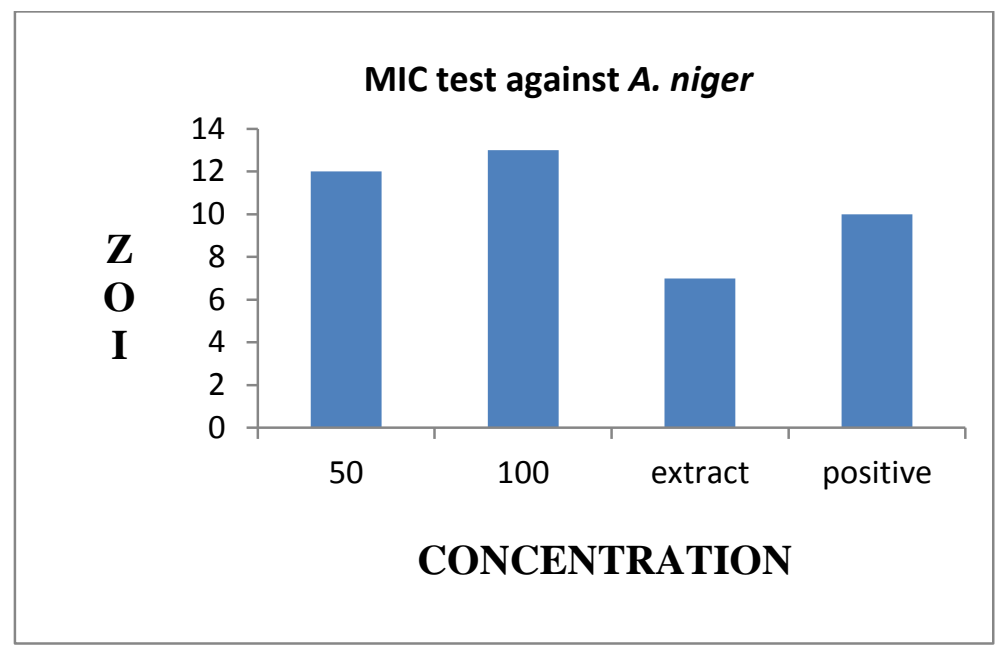

Graph 4: MIC Test against A.niger

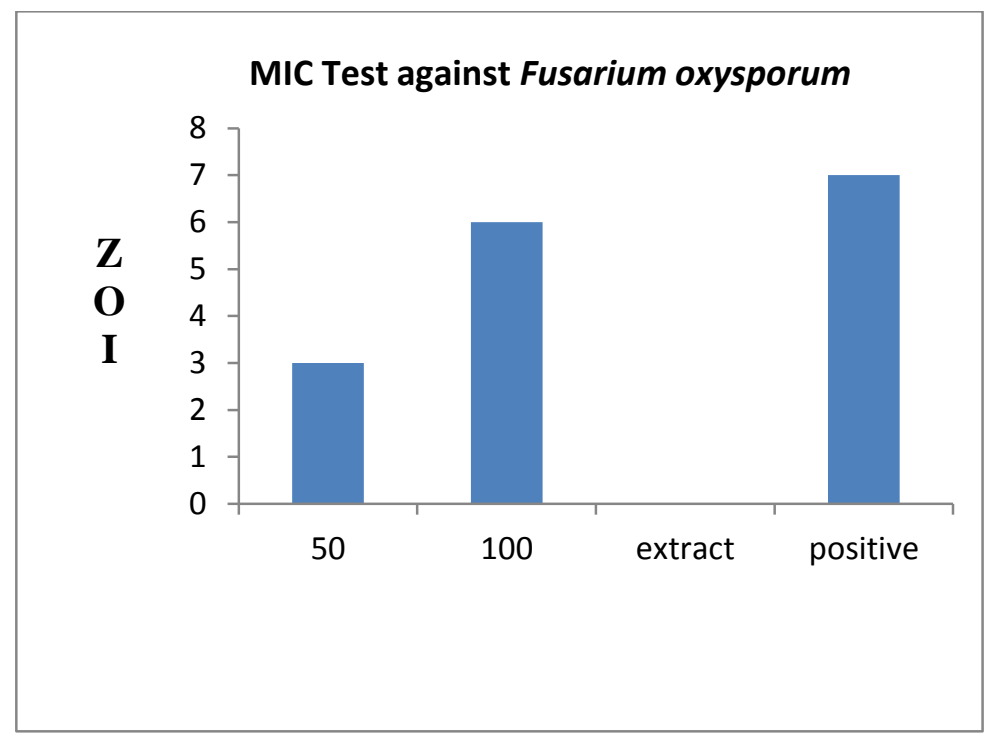

Graph 5: MIC Test against Fusarium Oxysporum 


\section{CONCLUSION:}

Synthesis of nanomaterial with the desired quality and properties is one of the key issues in current nanotechnology. Today, the green synthesis of metallic nanoparticles has received increasing attention due to the development of eco-friendly technologies in materials science. Use of natural plant extracts in the preparation of nanoparticles by greener route provides advancement over chemical and physical method as it is cost effective, environment friendly. In conclusion, here we report green and biological synthesis of $\mathrm{Cu}$ nanoparticles using leaf extract of Ficus racemosa. This method has advantageous over other reported methods are easily available starting materials, inexpensive and process is simple to carry in any college level laboratory, use of toxic reagent is avoided and pollution free.

\section{ACKNOWLEDGEMENTS}

Authors are grateful to Acube Lifesciences, Lucknow for the support and providing facilities to carry out this work.

\section{REFERENCES}

1. Cushing , B. L.; Kolesnichenko V. L. and C. J. O’Connor, "Recent advances in the liquid-phase syntheses of inorganic nanoparticles. Chemical Reviews 2004; vol. 104, no. 9, pp. 3893-3946

2. Jha, A.K., Prasad, K.; Prasad, K.; Kulkarni, A.R. Plant system: nature's Nano factory. Colloids and Surfaces B: Biointerfaces 2009; 73(2); 219-223.

3. Chopra,RN.; Chopra, IC.; Handa, KL.; Kapur, LD,Indigenous Drugs of India. 2nd edn, Academic 2007; 6(20), 725-730 .

4. Nadkarni, KM.; Nadkarni, AK.; Chopra RN. Indian Materia Medica, Vol. I, Popular Prakashan, Bombay. 1976; 548-550 .

5. Chopra, RN.; Chopra, IC and Verma BS, Supplement to Glossary of Indian Medicinal Plants, Indian Medicinal Plants-A Compendium of 500 Species 1996; III, 34-35.

6. Sastry, A.B.S.; Aamanchi, R.B.K.; Prasad, R.L. and Murthy B.S. Large-scale green synthesis of $\mathrm{Cu}$ nanoparticles. Environmental Chemistry Letters 2013; 11(2): 183187.

7. Elechiguerra, J.L.; Burt, J.L.; Morones, J.R.; CamachoBragado, A.; Gao, X.; Lara, H.H. and Yacaman, M.J. Interaction of silver nanoparticles with HIV-1. J Nanobiotechnology 2005; 3:6. doi:10.1186/1477-3155-3-6 . 
8. Obadoni, BO.; Ochuko PO Phytochemical studies and Comparative efficacy of the crude extracts of some homeostatic plants in Edo and Delta States of Nigeria. Global J. Pure Appl. Sci. 2001; 8: 203-208 .

9. 9.D.Jain.; H.K.Daima,S.; Kachhwaha,S.L.; Kothari, Digest Journal ofNanomaterials and Biostructures 2009;4, 557 .

10. K, Mujeeb.; K.Merajuddin, F.A. Syed.; N.T.Muhammad, T. Wolfgang.; Z. A Hamad, A. Abdulrahman, R.S.Mohammed, International Journal of Nanomedicine 2013; 8, 1507 .

11. Khan, SA.; Shahid, S.; Jameel M.; Ahmad A. In vitro Antibacterial, Antifungal and GC-MS Analysis of seeds of Mustard Brown. Int J Pharma Chem 2016; 6(4): 107115 .

12. Ren, G.; Hu D.; Cheng, EW.; Vargas-Reus MA, Reip P, Allaker RP. Characterization of copper oxide nanoparticles for antimicrobial applications. Int J Antimi Age 2009; 33(6): 587-590 . 